\title{
Inhaled transmembrane ion transport modulators and non-steroidal anti-inflammatory drugs in asthma
}

\author{
S Bianco, M Robuschi, A Vaghi, A Fumagalli, P Sestini
}

Several stimuli which affect the osmolarity of airway surface liquid may induce bronchoconstriction in asthmatic subjects, indicating that in these patients the control of the bronchial calibre is affected by the physicochemical characteristics of the airways lining fluid. ${ }^{1}$ In the last few years this hypothesis has been confirmed using a number of drugs which are known to affect cellular ion transport. ${ }^{2}$ Loop diuretics inhibit the bronchial obstructive response to ultrasonically nebulised distilled water (UNW) in a dose dependent fashion. ${ }^{3}$ It is still unclear, however, whether this protective activity is attributable to the main pharmacological activity of frusemide - the inhibition of the $\mathrm{Cl}^{-} /$ $\mathrm{Na}^{+} / \mathrm{K}^{+}$co-transport-since loop diuretics far more potent than frusemide on this mechanism, such as piretanide, torasemide or bumetanide, are markedly less effective than frusemide in preventing UNW induced bronchoconstriction when given by inhalation in equipotent diuretic doses (fig 1). ${ }^{4}$ In addition to UNW, frusemide was also found to be effective in reducing the bronchoconstriction induced by a variety of "indirect" stimuli including exercise, allergens, hyperosmotic aerosols, metabisulphite, and aspirin. ${ }^{45}$

The natriuretic activity of frusemide is known to be partially inhibited by cyclooxygenase (COX) inhibitors, and a single study found a complete abrogation of the protective effect of frusemide against exercise induced asthma after oral treatment with

Respiratory Diseases Clinic, University of Milan Bicocca, Ospedale S Gerardo, Monza, Italy

S Bianco

M Robuschi

A Fumagalli

Ospedale di

Garbagnate, Milan,

Italy

A Vaghi

Institute of Respiratory Diseases, University of Siena, Italy

P Sestini

Correspondence to: Dr P Sestini, Institute of Respiratory Diseases, Viale Bracci 3, 53100 Siena, Italy sestini@unisi.it

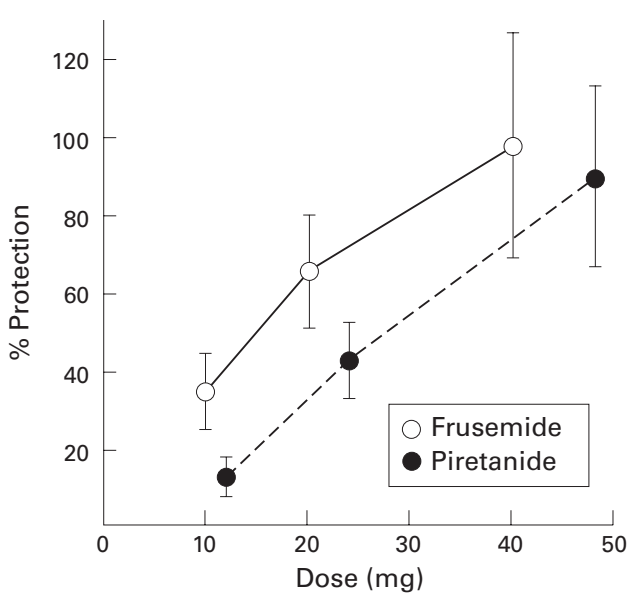

Figure 1 Protective effect against UNW induced bronchoconstriction of increasing doses of inhaled frusemide, administered from a pressurised metered canister (5 mg/puff) and piretanide administered through a jet nebuliser. Data are expressed as the percentage protection attained in the same patient using an optimal dose of $40 \mathrm{mg}$ frusemide through a jet nebuliser. Values are mean (SE) of 8-12 asthmatic patients. indomethacin. ${ }^{6}$ However, when we investigated whether aspirin like drugs would affect the bronchoprotective activity of this drug, we found that inhalation of lysine-aspirin had a potentiating - rather than an inhibitory-effect on the protective activity of inhaled frusemide against UNW induced bronchoconstriction. ${ }^{7}$ Inhaled sodium salicylate had no effect, suggesting that this activity could be due to COX inhibition. In further experiments we confirmed that inhaled COX inhibitors failed to abrogate the protective activity of frusemide against other stimuli such as allergen or exercise. ${ }^{45}$ Similarly, inhalation of lysineaspirin failed to inhibit the protective effect of torasemide $^{8}$ or of bumetanide ${ }^{9}$ against UNW induced bronchoconstriction. Furthermore, oral treatment with COX inhibitors failed to inhibit the protective activity of frusemide against bronchoconstriction induced by exercise, metabisulphite, UNW, ${ }^{4}$ and hypertonic saline. ${ }^{10}$ These observations, together with the lack of evidence that frusemide is able to induce production of prostaglandin $\mathrm{E}$ (PGE) by human epithelial cells, strongly argue against a role for prostaglandins in the protective activity of frusemide against bronchoconstriction. Nevertheless, aspirin like drugs are clearly able to affect airway responses, as shown by their ability to precipitate asthma attacks in sensitive patients ${ }^{11}$ or to attenuate the response to a variety of stimuli. ${ }^{12}$ Some of these activities, such as the protective activity against the early asthmatic response to allergen challenge, appear to be unrelated to their anti-COX potency. ${ }^{13}$ On the other hand, their ability to induce bronchoconstriction in aspirin sensitive patients is related mostly to their anti-COX-1 activity, since aspirin like drugs with prevalent anti-COX-2 activity such as carprofen, ${ }^{14}$ nimesulide, ${ }^{15}$ and meloxicam ${ }^{16}$ are relatively well tolerated by aspirin sensitive patients.

Chromones, which have been known for a long time for their protective activity against bronchoconstriction induced by a variety of stimuli, have recently been shown to inhibit chloride channels in vitro. ${ }^{17}$ This observation, together with the strong similarity in the spectrum of bronchoconstrictor stimuli against which frusemide and chromones exert their protective effect, suggest that these drugs may act through a similar mechanism related to ion transport regulation. Inhalation of lysineaspirin also failed to inhibit the protective activity of disodium cromoglycate, although it was not found to have a potentiating effect as observed with frusemide. ${ }^{18}$ 


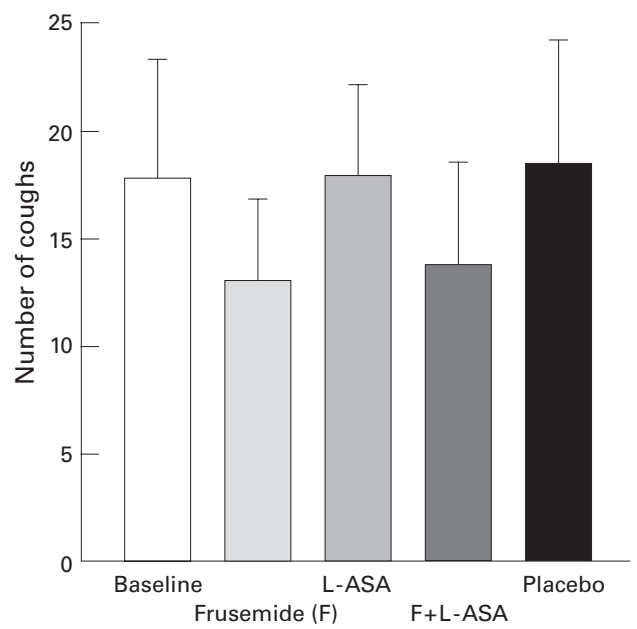

Figure 2 Lack of effect of inhalation of $40 \mathrm{mg}$ frusemide, 900 mg lysine-aspirin (L-ASA), or both on the cough response induced by inhalation of $4 \mathrm{ml}$ distilled water through an ultrasonic nebuliser. Data are mean (SE) of 11 normal subjects.

In addition to bronchial obstruction, osmolar stimuli also induce a cough response. However, despite their effectiveness in inhibiting bronchoconstriction induced by a variety of stimuli, both frusemide and chromones were found to have disappointingly little effect in inhibiting cough responses induced by osmotic as well as non-osmotic stimuli. ${ }^{5}$ Inhaled frusemide was found to reduce, to some extent, the cough response to low chloride solutions and to $\mathrm{PGF}_{2 \alpha}$, but we found no protection against citric acid induced cough after inhalation of frusemide, both alone or in combination with lysine-aspirin (fig 2). Similarly, no effect was found on the cough response to capsaicin and to metabisulphite. ${ }^{5}$

Ethanol is known to exert an antitussive effect when given by the oral route, an effect which was attributed to a central depressant effect. ${ }^{19}$ Ethanol exerts its central depressant effects by acting on transcellular ion transport

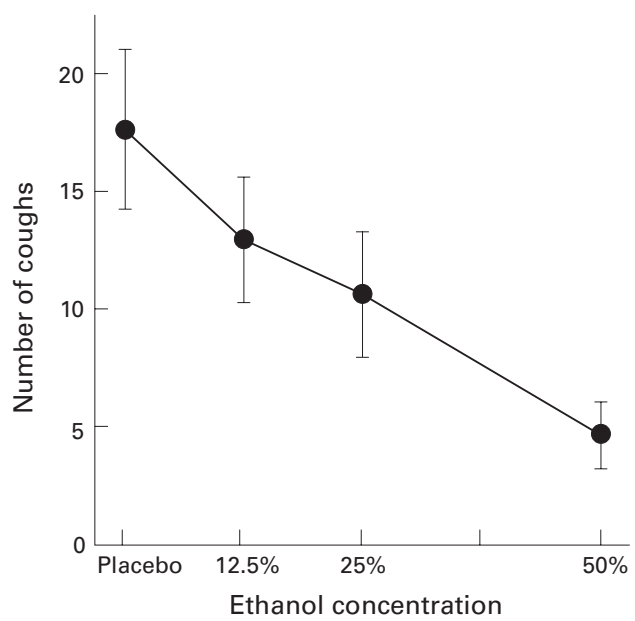

Figure 3 Mean cough response induced in seven normal subjects by inhalation through a Mefar dosimeter of 10 puffs of a single dose of citric acid at the concentration that caused at least 25 coughs in a preliminary challenge. On different days each subject performed the test one minute

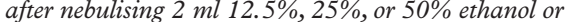
placebo through a Pari jet nebuliser manually activated during inspiration. Data are expressed as mean (SE). mechanisms. ${ }^{20}$ We therefore investigated whether ethanol inhalation could affect cough and bronchoconstrictor responses by acting on ethanol sensitive ion channels located in the airways. As shown in fig 3, inhaled ethanol was found to suppress the cough response to citric acid effectively in normal subjects. ${ }^{21}$ No detectable plasma levels of ethanol were reached in our experimental conditions, supporting the hypothesis that this effect is exerted through a local action rather than by a central sedative effect. The suppressive effect of inhaled ethanol against citric acid induced cough was found to be dose dependent and to last at least three hours. Capsaicin induced cough was also significantly suppressed by inhaled ethanol. ${ }^{22}$ These data suggest that ethanol sensitive ion channels are present in the airways and can modulate the cough response to irritant stimuli.

To investigate whether ethanol sensitive mechanisms could also modulate the obstructive responses of the airways, we investigated the effect of ethanol inhalation on UNW induced and exercise induced bronchoconstriction in patients with asthma. In a randomised, double blind study in 13 stable asthmatic subjects, inhalation of $2 \mathrm{ml} \mathrm{50 \%} \mathrm{ethanol}$ significantly reduced UNW sensitivity, causing UNW $\mathrm{PD}_{20}$ to increase from a mean (SE) of 11 (4) $\mathrm{ml}$ after placebo to 29 (6) $\mathrm{ml}$ after ethanol $(\mathrm{p}<0.03){ }^{23}$ In similar studies, ethanol was also found to afford good protection against exercise $^{24}$ and to exert a moderate but significant protective activity against hypertonic saline induced bronchoconstriction. ${ }^{25}$ By contrast, ethanol had no effect on methacholine induced bronchoconstriction ${ }^{26}$ and, in a few preliminary cases, no effect was found on the early asthmatic response to allergen challenge. Thus, although both ethanol and frusemide reduce UNW induced and exercise induced bronchoconstriction, the spectrum of stimuli responsive to these agents appears to be partially different as ethanol, but not frusemide, reduces cough induced by citric acid and capsaicin whereas the opposite is found for allergen induced bronchoconstriction.

In conclusion, studies using various drugs active on ion transport in the airways indicate that these mechanisms participate in the modulation of the airway response to a number of stimuli. Aspirin like drugs also protect against a variety of stimuli, but not all these activities appear to be related to COX inhibition. COX inhibition has no effect on the protective activity of loop diuretics, and aspirin induced asthma does not seems to be related to COX-2 inhibition. The identification of ethanol sensitive mechanisms of regulation of the airway responses might lead to the development of novel therapeutic strategies for the control of irritative tussigenic reactions.

1 Bianco S, Robuschi M, Sestini P, et al. Osmolarity, bronchial reactivity, and the protective effect of loop diuretics. In: Melillo G, Norman PS, Marone G, eds. Respiratory allergy. Melillo G, Norman PS, Marone G,

2 Bianco S, Robuschi M, Vaghi A, et al. Airway ion transport mechanisms and aspirin in asthma. In: Szczeklick A, Gryglewski RJ, Vane RV, eds. Eicosanoids, aspirin, and asthma. New York: Marcel Dekker, 1998: 419-38. 
3 Robuschi M, Gambaro G, Spagnotto S, et al. Inhaled furosemide $(\mathrm{F})$ is highly effective in preventing ultrasonically nebulized water $\left(\mathrm{UNH}_{2}\right.$

4 Bianco S, Pieroni M, Refini R, et al. Inhaled loop diuretics as potential new anti-asthmatic drugs. Eur Respir f 1993 6:130-4.

5 Bianco S, Pieroni MG, Refini RM, et al. Protective effect of inhaled loop diuretics on experimentally induced bronchoconstriction. In: Spector SH, ed. Provocation testing in clinical practice. New York: Marcel Dekker, 1995: 411-23.

6 Pavord ID, Wisniewski A, Tattersfield AE. Inhaled frusemide and exercise-induced asthma: evidence of a role for inhibiting prostanoids. Thorax 1992; 47:797-800

7 Bianco S, Vaghi A, Pieroni MG, et al. Potentiation of the antireactive, antiasthmatic effect of inhaled furosemide by inhaled lysine acetylsalicylate. Allergy 1993; 48:570-5.

8 Vaghi A, De Bernardi G, Sestini P, et al. Effect of inhaled lysine-aspirin on the protective activity of bumetanide lysine-aspirin on the protective activity of bumetanide 1996:9(Suppl 23):33s.

9 Grassi N, Vaghi A, DeBernardi G, et al. Effect of inhaled lysine aspirin on the protective activity of torasemide against ultrasonically nebulized distilled water. Eur Respir $\mathcal{F}$ 1999;14(Suppl 30):530

10 Rodwell LT, Anderson SD, Spring J, et al. Effect of inhaled frusemide and oral indomethacin on the airway response to hypertonic saline challenge in asthmatic subjects. Thorax 1997;52:59-66.

11 Szczeklik A, Stevenson DD. Aspirin-induced asthma: advances in pathogenesis and management. F Allergy Clin Immunol 1999;104:5-13

12 Bianco S, Pieroni MG, Refini RM, et al. Could NSAIDs have a role as antiasthmatic agents? Drugs 1994;48:9-15.

13 Sestini P, Refini RM, Pieroni MG, et al. Different effects of inhaled aspirin-like drugs on allergen-induced early and late asthmatic responses. Am $\mathcal{F}$ Respir Crit Care Med, 1999; 159:1229-33.

14 Bianco S, Robuschi M, Simone P, et al. Tolerance of carprofen in patients with asthma caused by non-steroidal anti-inflammatory drugs. F Int Med Res 1985;13:294-9.
15 Bianco S, Robuschi M, Petrigni G, et al. Efficacy and tolerability of nimesulide in asthmatic patients intolerant to aspirin. Drugs 1993;46(Suppl 1):115-20.

16 Vaghi A, Debernardi G, Grassi N, et al. Tolerance of the COX-2 inhibitor, meloxicam, in aspirin-sensitive asthmatics. Eur Respir F 1997;10:476s.

17 Romanin Chr, Reinsprecht M, Pecht I, et al. The antiallergic drug cromolyn is a potent blocker of $\mathrm{Cl}^{-}$channel activity in rat mucosal mast cells (RBL-2H3 line). Nayun Sch Arch Pharmacol 1991;343:313

18 Sestini P, Robuschi M, Vaghi A, et al. Effect of inhaled lysine acetylsalicylate on the protective activity of cromolyn sodium against the bronchial obstructive response to ultrasonically nebulized water. Am Rev Respir Dis 1993;147: $836 \mathrm{~A}$.

19 Berkowitz H, Reichel J, Shim C. The effect of ethanol on the cough reflex. Clin Sci Mol Med 1973;45:527-31.

20 Hobbs WR, Rall TW, Verdoorn TA. Hypnotics and sedatives:ethanol. In: Goodman E Gillman's pharmacological basis of therapeutics. 9th ed. New York: McGraw-Hill, 1996: 361-96.

21 Fumagalli A, Busia A, Vernocchi S, et al. Effect of ethanol on citric acid induced cough. Eur Respir $\mathcal{F}$ 1999;14(Suppl 30): $533 \mathrm{~s}$.

22 Fumagalli A, Bianchi A, Turati A, et al. Effect of inhaled ethanol on capsaicin-induced cough. Am f Respir Crit Care Med 1999;159:A534

23 Fumagalli A, Busia A, Pieroni MG, et al. Effect of ethanol on bronchoconstriction induced by ultrasonically nebulized distilled water. Eur Respir f 1999;14(Suppl 30):532s.

24 Bianchi A, Molteni LP, Fumagalli A, et al. Prevention of exercise-induced asthma by inhaled ethanol. Eur Respir $\mathcal{F}$ 1999;14(Suppl 30):532-3s

25 Grassi N, Vaghi A, DeBernardi G, et al. Effect of inhaled ethanol on hypertonic saline-induced bronchoconstriction. Eur Respir f 1999;14(Suppl 30):532s.

26 Fumagalli A, Bianchi A, Vernocchi S, et al. Effect of ethanol on methacholine-induced bronchoconstriction. Eur Respir f 1999;14(Suppl 30):532s 